\title{
Critical Current Variation as a Function of Transverse Stress of Bi-2212 Rutherford Cables
}

\author{
Daniel R. Dietderich, Ronald M. Scanlan, Takayo Hasegawa, Yuji Aoki, Robert S. Sokolowski, and \\ Leszck R. Motowidlo
}

\begin{abstract}
Transverse loading experiments on wire has shown that a significant drop in critical current occurs for stresses greater than 50 MPa. However, many high-energy physics applications require that the $\mathrm{Bi}_{2} \mathrm{Sr}_{2} \mathrm{CaCu}_{2} \mathrm{O}_{8}$ conductor withstand stresses greater than $100 \mathrm{MPa}$ without permanent degradation. Therefore, a study of epoxy impregnated cables, identical to those used in accelerator magnet applications, has been performed. This work presents the first results of Rutherford cables of $\mathrm{Bi}_{2} \mathrm{Sr}_{2} \mathrm{CaCu}_{2} \mathrm{O}_{8}$ with transverse stress. The results show that the cable can withstand stresses up to $60 \mathrm{MPa}$ with a strain of about $0.3 \%$ for the face loading orientation and $100 \mathrm{MPa}$ for the edge loading orientation.
\end{abstract}

Index Terms-Bi-2212, cables, critical current, and stress.

\section{INTRODUCTION}

$\mathrm{F}_{\mathrm{s}}$ or the production of dipole fields above $15 \mathrm{~T}$, $\mathrm{Bi}_{2} \mathrm{Sr}_{2} \mathrm{CaCu}_{2} \mathrm{O}_{8}$ (Bi-2212) may be an attractive alternative to $\mathrm{Nb}_{3} \mathrm{Sn}$. The main advantage is the low field dependence of $\mathrm{Bi}-2212$ in the 15-20 $\mathrm{T}$ range, where the critical current density of $\mathrm{Nb}_{3} \mathrm{Sn}$ decreases rapidly. However, before this advantage can be realized, the engineering $J_{c}$ must be improved and the $J_{c}$ variation with transverse stress and strain behavior must be understood. Continual improvement in the critical current is presented at this conference in the paper by Aoki, et al. with $\mathrm{I}_{\mathrm{c}}$ 's greater that $250 \mathrm{~A}$ at $12 \mathrm{~T}$ and $\mathrm{J}_{\mathrm{c}}$ 's greater than 1750 $\mathrm{A} / \mathrm{mm}^{2}$ [1]. This paper describes some of the first experiments aimed at understanding the $\mathrm{J}_{\mathrm{c}}$ variation with transverse strain behavior of $\mathrm{Bi}-2212$ cables.

Manuscript received September 19, 2000. This work was supported by the director, Office of Energy Research, Office of High Energy and Nuclear Physics, High Energy Physics Division, U.S. Department of Energy, under Contract No. DE-AC03-76SF00098.

D. R. Dietderich and R. M. Scanlan are at Lawrence Berkeley National Laboratory, Berkeley, CA 94720 USA (telephone: 510-4866087, e-mail: drdietderich@lbl.gov or rmscanlan@lbl.gov.

T. Hasegawa and Y. Aoki are at Showa Electric Wire \& Cable Co. Ltd, Kawasaki, Japan.

R. S. Sokolovsky and L. R. Motowidlo are at Intermagnetics General Corporation, Latham, NY 12110, USA.

\section{EXPERIMENTAL DETAILS}

The testing procedure for the $\mathrm{Bi}-2212$ cables presented in this paper was the same as that reported previously for $\mathrm{Nb}_{3} \mathrm{Sn}$ cables [2]. Briefly, the cables are insulated with Sglass, placed in stainless steel test tooling, and vacuum impregnated with CTD-101 epoxy.

One cable used in this work, number 689 (fig. 1), contained 20 strands of $\mathrm{Bi}-2212$ wire from billet number K288. It had a core of Ni-Cr $80(6.3 \mathrm{~mm}$ by $0.1 \mathrm{~mm})$ covered with two-layer wrap of $\mathrm{MgO}$ paper. The cable had the nominal dimensions of $2.240 \mathrm{~mm}$ thick and $8.890 \mathrm{~mm}$ wide. It was difficult to obtain a precise thickness measurement due to the soft $\mathrm{MgO}$ tape around the core. A thickness of $2.140 \mathrm{~mm}$ is obtained if the cable is firmly compressed during the measurement. Typically for $\mathrm{Nb}_{3} \mathrm{Sn}$ cable the compacted dimension is used when the cable is assembled into the reaction and test tooling. However, this was not the case for the Bi-2212 cables. During reaction the cable was not confined to its nominal dimensions in a reaction fixture since the cable expanded during reaction. Therefore, the post-reaction cable dimensions were used so that the conductor would not be strained during assembly in the test tooling. The post-reaction thickness and width were $2.348 \mathrm{~mm}$ and $8.94 \mathrm{~mm}$, respectively.

The cable was reacted on a large spool with a diameter of $300 \mathrm{~mm}$ to minimize any damage from bending the cable during magnet winding or preparing for these tests.

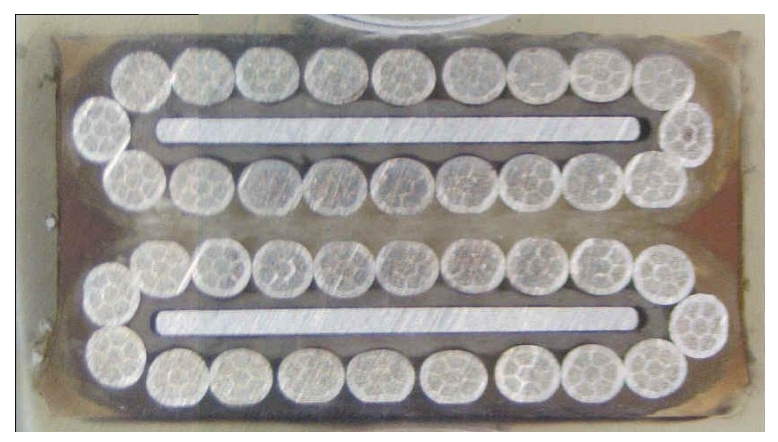

Fig. 1. Optical photograph of two cables of 689. The cross-section shows the potted cables as measure in face loading. The cable thickness and width were $2.35 \mathrm{~mm}$ and $8.94 \mathrm{~mm}$, respectively. 


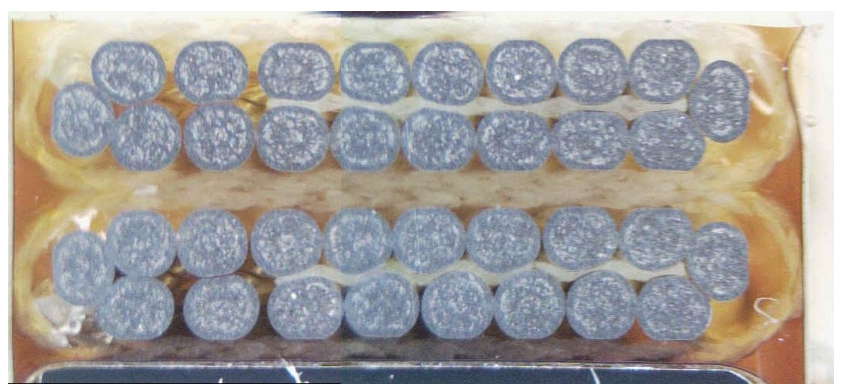

Fig. 2. Optical photograph of two cables of 734. The cross-section shows the potted cables as measure in face loading. The cable thickness and width were $1.47 \mathrm{~mm}$ and $8.13 \mathrm{~mm}$, respectively.

Insulation was placed between the layers to prevent sintering of adjacent cable. The cable was taken off of the reaction spool and placed on a spool for shipment from Showa to Lawrence Berkeley National Laboratory. The cable was unwound from the shipping spool, straightened, and placed into the test tooling. The calculated bending strain that the cable sustained was less than $1 \%$.

The second cable, number 734 (fig. 2) was produced with 18 strands with a pure Ag matrix. This cable only had an $\mathrm{MgO}$ tape core that extended about $3 / 4$ of the width of the cable as can be seen in Fig. 2. This sample was reacted straight in tooling such that it maintained the dimensions obtained during cabling.

A potential criteria of $1 \mu \mathrm{V} / \mathrm{cm}$ was used to determining the critical current of cable 689. Since the voltage taps on all of the cable are $17 \mathrm{~cm}$ apart the voltage criteria was of $1.7 \mu \mathrm{V}$.

\section{RESULTS AND DISCUSSION}

The first measurements of the effect of transverse stress on the critical current of Bi-2212 wire has shown that the critical current dropped significantly for stresses as low as 10-20 MPa [3]. This paper reports the first measurements of transverse stress on Rutherford cable. Figures 3 and 4 show that a significant drop in $I_{c}$ does not occur until the stress is greater than $60 \mathrm{MPa}$ for the face

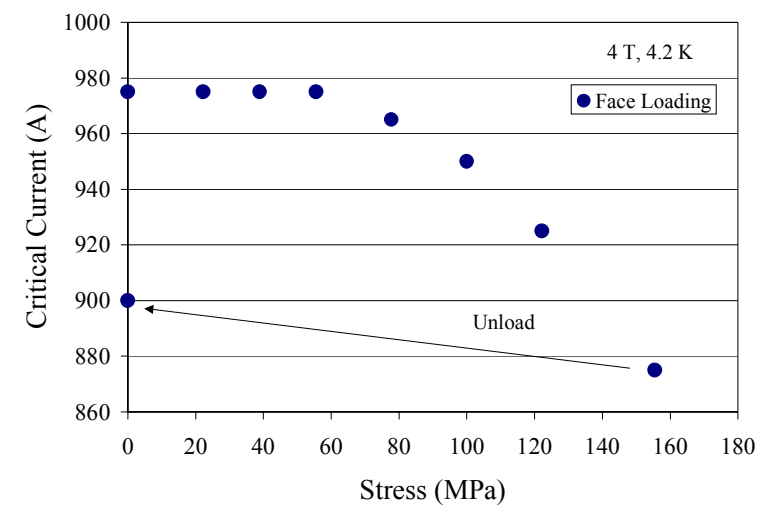

Fig. 3. Variation of the critical current $(4 \mathrm{~T}, 4 \mathrm{~K})$ with stress for a cable loaded on the broad face of the cable.

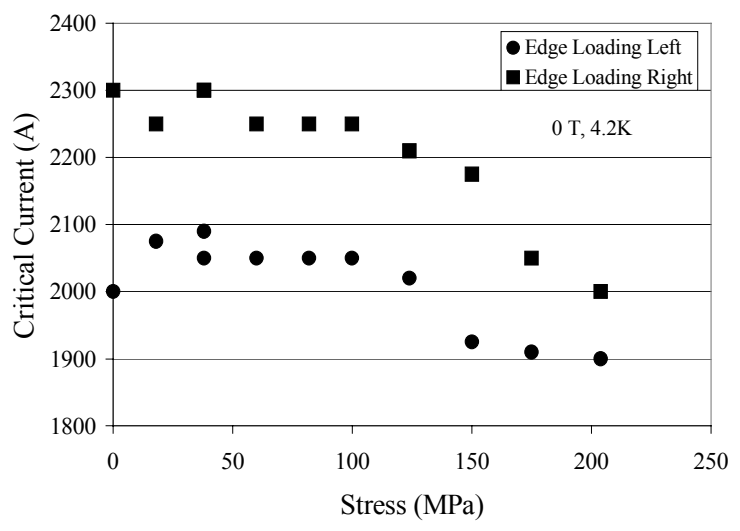

Fig. 4. Variation of the critical current (self-field, $4 \mathrm{~K}$ ) with stress for a cable loaded on the edge of the cable.

loading orientation and about 100MPa for the edge loading orientation. It can also be seen in Fig. 3 that when the load is removed the $I_{c}$ reduction is permanent.

The $I_{c}$ of the cable measured in self-field (Fig. 4) is less than what one would expect from 20 times a single stand (i.e. 3,300 A). This decrease is more than one would calculate due to self-field effects in the cable, and the origin of the decrease is not known at this time. One source could be that the strands are damaged during cabling. However, previous results on strands that have been extracted from cable, heat-treated, and $\mathrm{I}_{\mathrm{c}}$ measured have shown no loss in current carrying capacity [4]. Also, the VI curves of fig. 5 suggest that the cables have not been damaged. The curves of fig. 5 give n-values of 7-12 that are low by $\mathrm{Nb}_{3} \mathrm{Sn}$ standards but are representative of those observed in Bi-2212 conductors. The possibility of damage during assembly into the test tooling cannot be ruled out. The other possibility is that the cable is not uniformly heat treated due to its long length such that every section does not receive the optimum temperature for the appropriate time. These various factors can only be determined by measurements on future cables.

An estimate of the overall strain of the face loading cable stack can be obtained. Mechanical modeling of the cable stack in the face loading orientation for a load of

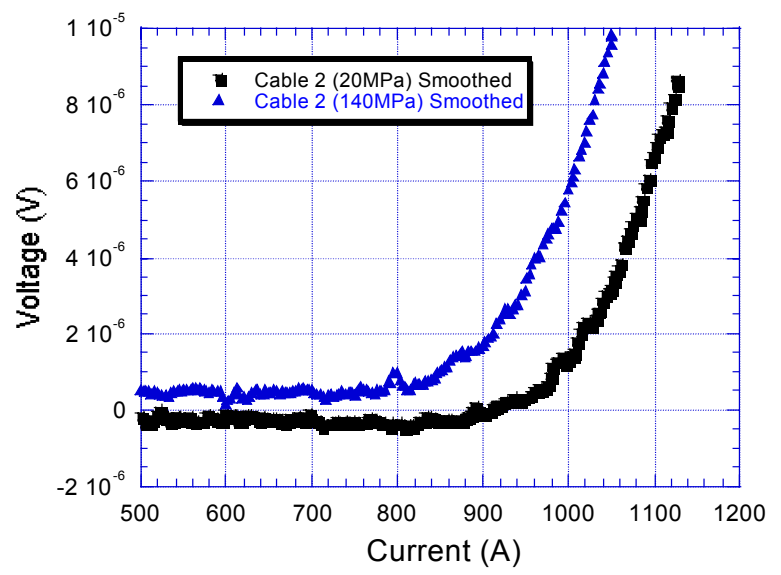

Fig. 5. Voltage-current curves at $4 \mathrm{~T}$ and $4.2 \mathrm{~K}$ of cable 689 for stresses of $20 \mathrm{MPa}$ and $140 \mathrm{MPa}$. 


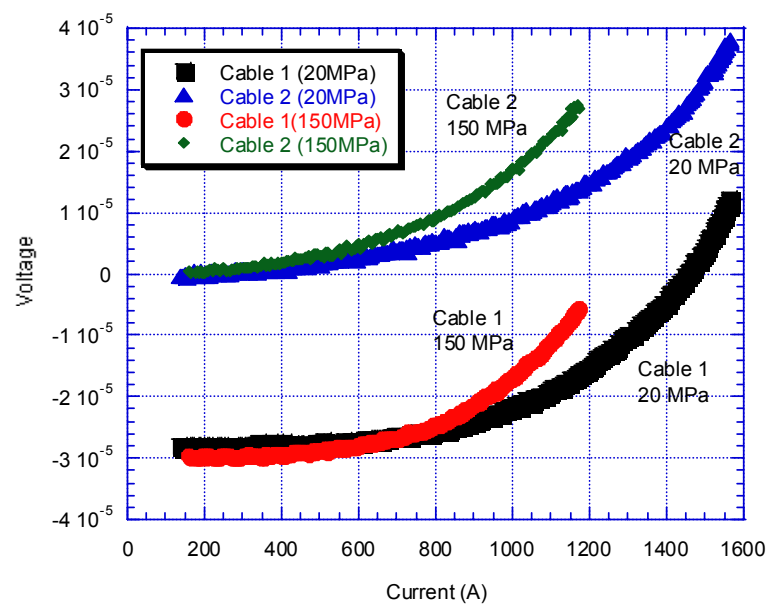

Fig. 6. Voltage-current curves at $8 \mathrm{~T}$ and $4.2 \mathrm{~K}$ of cable 734 for stresses of $20 \mathrm{MPa}$ and $150 \mathrm{MPa}$. The top two curves are for cable 2 and the bottom curves two are for cable 1 .

$100 \mathrm{MPa}$ gives a displacement of the steel beam into the cable package of about $25 \mu \mathrm{m}$. Using this value for the compaction of the stack and a stack thickness of $5 \mathrm{~mm}$ gives a strain of about $0.5 \%$. Therefore, at $60 \mathrm{MPa}$ the strain would be about $0.3 \%$. This is about the irreversible strain limit observed for $\mathrm{Bi}-2223$ and $\mathrm{Bi}-2212$ [5], [6]. Comparison of these results and the work on wires show that a better method to extrapolate wire data to cables is required. In the future precise measurement of the strain in wire and cable that are being loaded transversely should facilitate the comparison.

Unfortunately, cable 734 was damaged after reaction. This can be seen in the broad V-I curves of Fig. 6. Also, the $I_{c}$ is about a factor of two less than an identical cable tested in parallel field [1]. Nevertheless, the results obtained show that this cable is also not very sensitive to stress. If one uses a criteria of $10 \mu \mathrm{V}$ the $\mathrm{I}_{\mathrm{c}}(8 \mathrm{~T}, 4.2 \mathrm{~K}, 20$ $\mathrm{MPa})$ of cable 1 and 2 are $1,150 \mathrm{~A}$ and $1,050 \mathrm{~A}$, respectively. The critical currents of the same cables measured at $150 \mathrm{MPa}$ have $\mathrm{I}_{\mathrm{c}}$ 's of $925 \mathrm{~A}$ and $850 \mathrm{~A}$, respectively for cables 1 and 2 .

The newest Bi-2212 strand being produced has a much higher critical current than that obtained in these cables.
Presently, the $I_{c}$ of state of the art Bi-2212 wires produce $I_{c}$ of $650 \mathrm{~A}$ in self field and $250 \mathrm{~A}$ at $12 \mathrm{~T}$. These results are being presented at this conference [1]. It has yet to be determined if cables made with the best material will also have low stress sensitivity or be less susceptible to $I_{c}$ reduction with cyclical loading [6].

\section{CONCLUSIONS}

These results show that $\mathrm{Bi}-2212$ conductor can withstand large stresses as long as the strand is well supported in a fiberglass-reinforced epoxy matrix. The important design parameter, as well as the best parameter for comparing strand and cable results, is the amount of local strain the strand is subjected too, which is much less than that observed in an unsupported wire for similar stresses.

\section{REFERENCES}

[1] Y. Aoki, N. Ohtani, T. Koizumi, T. Hasegawa, L. R. Motowidlo, R. S. Sokolowski, R. M. Scanlan, and S. Nagaya, "Improvement of superconducting properties of Bi-2212 round wire and primary test results of large capacity Rutherford cable," these proceedings.

[2] D. R. Dietderich, R. M. Scanlan, R. P. Walsh, and J. R. Miller, "Critical current of superconducting Rutherford cable in high magnetic fields with transverse pressure," IEEE Trans. Superconductivity, vol. 9, June 1999, pp. 122-125.

[3] J. Ekin, National Institute for Standards and Technology, Boulder, CO, private communication, 1999.

[4] R. M. Scanlan, D. R. Dietderich, H. C. Higley, K. R. Marken, L. R. Motowidlo, R. S. Sokolowski, and T. Hasegawa, "Fabrication and test results for Ruthrford-type cables made from BSCCO strands," IEEE Trans. Superconductivity, vol. 9, June 1999, pp. 130-133.

[5] B. ten Hakken, A. Goddeke, H. J. Schuver, H. H. J. ten Kate, "Strain reduced critical current in $\mathrm{Bi}-2223 / \mathrm{Ag}$ superconductors under axial tension and compression," Adv. in Cryo. Eng., 42A, 1997, pp. 651-658.

[6] B. ten Hakken, A Beuink, and H. H. J. ten Kate, "Small and repetitive axial strain reducing the critical current in $\mathrm{BSCCO} / \mathrm{Ag}$ superconductors," IEEE Trans. Appl. Superconductivity, vol. 7, June 1997, pp. 2034-2037. 